Technological University Dublin

DƯBLIN

ARROW@TU Dublin

\title{
The Effect of the Rate of Precursor Production on the Purity and Aggregation Morphology of Nanoparticulate Zinc Oxide
}

\author{
Grainne Duffy \\ Suresh Pillai \\ Technological University Dublin, suresh.pillai@tudublin.ie \\ Declan McCormack \\ Technological University Dublin, Declan.mccormack@tudublin.ie
}

Follow this and additional works at: https://arrow.tudublin.ie/cenresart

Part of the Materials Science and Engineering Commons

\section{Recommended Citation}

Grainne Duffy, Suresh C. Pillai, Declan E. McCormack (2007) The effect of the rate of precursor production on the purity and aggregation morphology of nanoparticulate zinc oxide. Journal of materials chemistry, 17, 2007, 181-184. doi:10.1039/b610947k

This Article is brought to you for free and open access by the Crest: Centre for Research in Engineering Surface Technology at ARROW@TU Dublin. It has been accepted for inclusion in Articles by an authorized administrator of ARROW@TU Dublin. For more information, please contact arrow.admin@tudublin.ie, aisling.coyne@tudublin.ie,gerard.connolly@tudublin.ie.

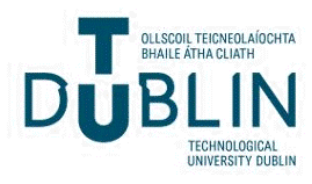




\title{
The effect of the rate of precursor production on the purity and aggregation morphology of nanoparticulate zinc oxide $\dagger$
}

\author{
Gráinne M. Duffy, ${ }^{a}{ }^{\text {Suresh C. Pillai }}{ }^{b}$ and Declan E. McCormack*a \\ Received 31st July 2006, Accepted 3rd October 2006 \\ First published as an Advance Article on the web 12th October 2006 \\ DOI: 10.1039/b610947k
}

The synthesis of zinc oxide through the decomposition of a solid oxalate precursor was investigated. It was found that the rate of preparation of the precursor had a quantitative effect on the morphology and extent of surface ligation of particles produced; contrary to our expectations, it was found that the slow combination of reagents led to a less pure product. It has been determined that this time dependence mimics the variation of reactant ratios. Zinc oxide particles were produced from a number of reactant ratios, and were characterised by TEM, XRD, FT-IR and DSC. It was found that the size of the crystallites produced was not affected, but that the nature of their surface ligation did rely upon these parameters.

\section{Introduction}

Zinc oxide is a wide, direct bandgap semiconductor which has been used in areas such as catalysis, ${ }^{1,2}$ gas sensing, ${ }^{3}$ lasing, ${ }^{4}$ in surface acoustic wave filters, ${ }^{5}$ as a piezoelectric actuator, ${ }^{6}$ in the production of varistors, ${ }^{7}$ and as a transparent conducting oxide layer for solar cell applications. ${ }^{8,9}$ While numerous methods of synthesis of zinc oxide films and structures have been investigated, the sol-gel route is favourable because of its low cost and the non-destructive nature of the processing conditions involved. The number of synthesis methods reported illustrates the ease with which zinc oxide can be made, and controlling the size and shape presents a challenge. The decomposition of oxalate precursors provides a simple, inexpensive means for its production as a nanocrystalline powder. ${ }^{10}$ This route relies upon the synthesis of polymeric oxalate precursor gels, ${ }^{11-14}$ which decompose on heating to yield nanoparticulate zinc oxide.

The morphology of these powders has been shown to be dependent on the solvent used and the presence of a polyol and/or surfactant molecules. ${ }^{15,16}$ Here, we establish a relationship between the rate and concentration of oxalic acid molecules added, and the aggregation behaviour and amount of surface ligation of the particles produced. It is shown that particles synthesised through a rapid combination of reagents possess more favoured properties.

\section{Experimental}

\section{Materials}

Zinc acetate dihydrate $\left(\mathrm{Zn}\left(\mathrm{CH}_{3} \mathrm{COO}\right)_{2} \cdot 2 \mathrm{H}_{2} \mathrm{O}\right.$, Sigma-Aldrich, $98 \%)$, oxalic acid dihydrate $\left(\mathrm{C}_{2} \mathrm{H}_{2} \mathrm{O}_{4} \cdot 2 \mathrm{H}_{2} \mathrm{O}\right.$, Sigma-Aldrich,

${ }^{a}$ School of Chemical and Pharmaceutical Sciences, Dublin Institute of Technology, Dublin 8, Ireland. E-mail: declan.mccormack@dit.ie; Fax: +353 1402 4989; Tel: +3531402 4778

${ }^{b}$ Centre for Research in Engineering Surface Technology, Dublin Institute of Technology,Dublin 8, Ireland.E-mail: suresh.pillai@dit.ie; Fax: +353 1402 7941; Tel: +35314027946

$\dagger$ Electronic supplementary information (ESI) available: FT-IR data. See DOI: $10.1039 / \mathrm{b} 610947 \mathrm{k}$
99\%), absolute ethanol $\left(\mathrm{C}_{2} \mathrm{H}_{5} \mathrm{OH}\right.$, Sigma, >99.5\%), acetic acid $\left(\mathrm{CH}_{3} \mathrm{COOH}\right.$, Sigma-Aldrich, $\left.>99.7 \%\right)$, and potassium bromide (KBr, Aldrich, IR grade, 99.99\%) were used without further purification.

\section{Synthesis}

Stock solutions of $1 \mathrm{mmol}(0.219 \mathrm{~g})$ zinc acetate dihydrate in $10 \mathrm{ml}$ ethanol, or an equal ratio, were prepared by stirring at $50{ }^{\circ} \mathrm{C}$ for $30 \mathrm{~min}$. Likewise, the required quantity of oxalic acid, dissolved under stirring at room temperature in $10 \mathrm{ml}$ ethanol or at an equivalent concentration, was prepared. In a typical experiment $1 \mathrm{mmol}(0.219 \mathrm{~g})$ zinc acetate dihydrate was reacted with $1 \mathrm{mmol}$ of oxalic acid dihydrate $(0.126 \mathrm{~g})$ to produce the $1: 1$ product. These solutions were combined and stirred at room temperature for $30 \mathrm{~min}$. The precursor formed was then dried at $100{ }^{\circ} \mathrm{C}$ in an oven, ground, and calcined in a muffle furnace at a ramp rate of $10{ }^{\circ} \mathrm{C} \mathrm{min}{ }^{-1}$ to the required temperature, with a dwell time of one hour at this temperature.

\section{Characterisation}

X-Ray diffraction patterns were recorded for $2 \theta$ values between $10^{\circ}$ and $80^{\circ}$ on a Siemens D500 XRD, at $25^{\circ} \mathrm{C}$ using $\mathrm{Cu} \mathrm{K} \mathrm{K}_{\alpha}$ radiation operating at $40 \mathrm{kV}$ and $30 \mathrm{~mA}$. Powders were prepared by dropcasting from an isopropanoloic slurry an opaque layer of the material on a clean glass slide and allowing to dry under ambient conditions.

Transmission mode FT-IR spectra were obtained between $4000 \mathrm{~cm}^{-1}$ and $375 \mathrm{~cm}^{-1}$ using a Perkin-Elmer Spectrum GX infrared spectrometer. Potassium bromide was used as a $10: 1$ diluent and the finely ground mixtures were pressed under 15 tonnes to obtain a homogeneous disc. Reference spectra of a disc containing $\mathrm{KBr}$ only were obtained before the acquisition of spectra.

TEM images of the particles were obtained on a Hitachi 7000 TEM.

Thermal analysis of the precursor powders to $500{ }^{\circ} \mathrm{C}$ was performed using a Rheometric QC DSC with ramp rate of $5{ }^{\circ} \mathrm{C} \min ^{-1}$ under flowing nitrogen. 


\section{Results and discussion}

Precursor solutions were prepared by the addition of oxalic acid dropwise over $30 \mathrm{~min}$, and rapidly in less than $1 \mathrm{~min}$. In both cases, after a $30 \mathrm{~min}$ stirring step, these solutions were divided into aliquots, and calcined to temperatures between $300{ }^{\circ} \mathrm{C}$ and $500{ }^{\circ} \mathrm{C}$.

The temperature evolution of the powders prepared by rapid addition was examined by XRD and is shown in Fig. 1. Powders calcined to $375{ }^{\circ} \mathrm{C}$ and above exhibited peaks that could be indexed to wurtzite zinc oxide, of increasing intensity. Crystalline peaks related to zinc oxide were not found in samples calcined at $300{ }^{\circ} \mathrm{C}$. Powders calcined to $350{ }^{\circ} \mathrm{C}$ showed a zinc oxide pattern, along with some lower intensity peaks. These low intensity peaks were present at the same $2 \theta$ values as the strong peaks present in the sample calcined to $300{ }^{\circ} \mathrm{C}$, and may thus have been evidence for residual precursor material at $350{ }^{\circ} \mathrm{C}$. The powders synthesized through slow combination of reagents showed the same trend, however, several of the prominent peaks found in the $300{ }^{\circ} \mathrm{C}$ pattern in Fig. 1 were absent in this series. The peaks common to both samples can be indexed to zinc oxalate hydrate, ${ }^{17}$ those found only in the rapidly synthesized precursor can be associated with anhydrous zinc oxalate, ${ }^{18}$ along with some unidentified, low intensity, peaks.

The thermal decomposition of the powders was examined using DSC, and is shown in Fig. 2. Both precursors showed a
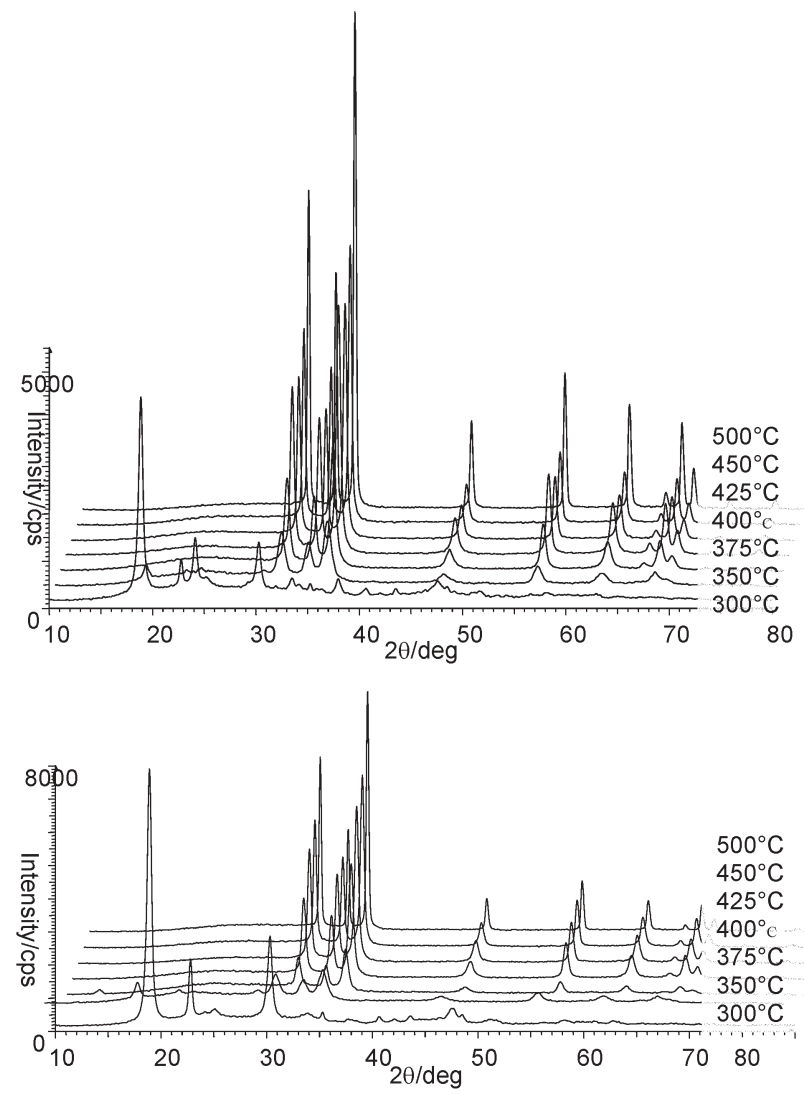

Fig. 1 X-Ray diffractograms of powders synthesized by (top) rapid and (bottom) slow combination of reagents, and calcined to various temperatures between $300{ }^{\circ} \mathrm{C}$ and $500{ }^{\circ} \mathrm{C}$.

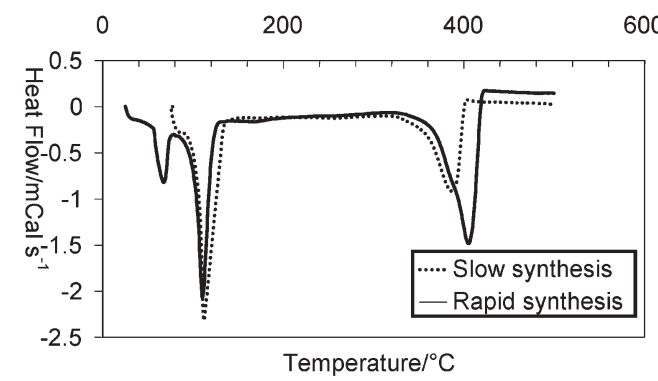

Fig. 2 Thermal decomposition of precursor powders synthesized by both methods.

broad endotherm at $100{ }^{\circ} \mathrm{C}$, related to the loss of bulk water, and another between $350{ }^{\circ} \mathrm{C}$ and $400{ }^{\circ} \mathrm{C}$. The latter peak supports the XRD data presented above, indicating the decomposition of oxalate precursor and formation of zinc oxide. It is of interest to note that, while both samples contain the same reagents in the same ratios, and the different sample masses have been accounted for, this endotherm was substantially greater in the case of the rapidly synthesized material. It can also be seen that the precursor formed through slow combination of reagents had decomposed completely by $400{ }^{\circ} \mathrm{C}$, whereas that formed through their rapid combination persisted to slightly higher temperatures.

TEM images of particles synthesized through both methods and calcined to $350{ }^{\circ} \mathrm{C}$ are shown in Fig. 3. The striking difference in morphology can be seen from these images; particles synthesized through slow combination showed a characteristic linear aggregation structure, while those synthesized through rapid combination of reagents had a more lamellar character. Analysis of the particles revealed that those synthesized through rapid combination had slightly larger average diameter than those synthesized through slow

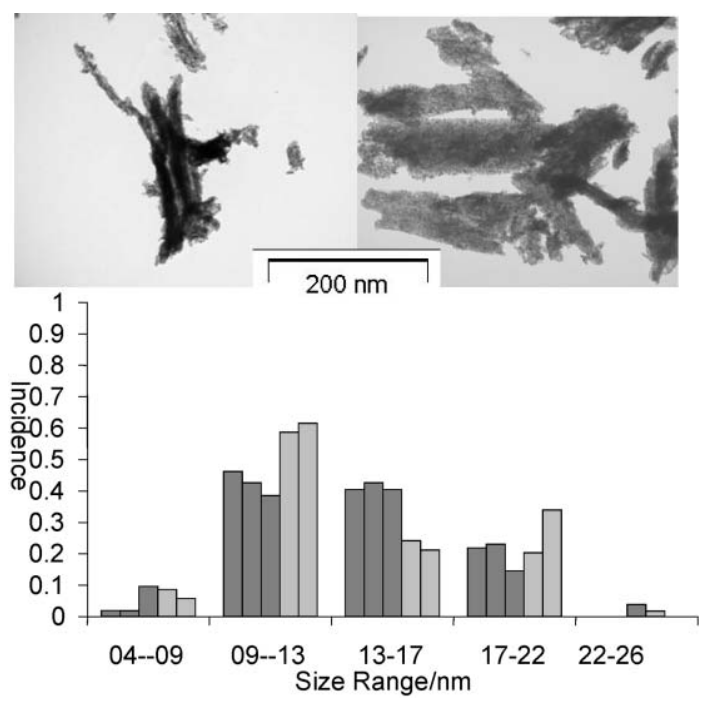

Fig. 3 Above, TEM images of powders synthesized through (left) rapid and (right) slow combination of reagents and calcined to $350{ }^{\circ} \mathrm{C}$, $50000 \times$. Below, size distribution of these particles; the darker bars are indicative of particle size for the slow combination of reagents whereas the lighter bars are indicative of particles formed by rapid combination. 


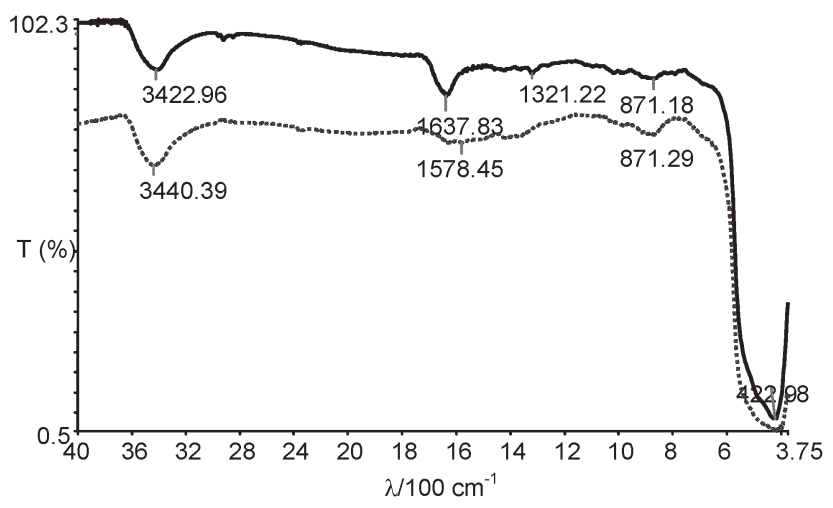

Fig. 4 FT-IR spectra of powders synthesized slowly (top) and rapidly (bottom), and calcined to $375{ }^{\circ} \mathrm{C}$.

addition, with a mean size difference of approximately $1 \mathrm{~nm}$. Larger particle sizes and a greater extent of aggregation are understandable in the context of the synthesis method involved, the difference in aggregation behaviour is not.

From both XRD and DSC we can seen that this reaction is complete after calcination to $425{ }^{\circ} \mathrm{C}$. FT-IR spectroscopy of powders calcined to $375{ }^{\circ} \mathrm{C}$ was undertaken in order to establish their purity, and is shown in Fig. 4. These spectra shared a number of characteristics; a peak at $3400 \mathrm{~cm}^{-1}$ due to the presence of atmospheric water, weak peaks at $870 \mathrm{~cm}^{-1}$ that can be related to surface ligation, and a strong zinc oxide peak at $423 \mathrm{~cm}^{-1}$. The powder synthesized slowly also showed a carboxyl peak at $1637 \mathrm{~cm}^{-1}$, this was not present in the rapidly synthesized sample heated to this temperature. This carboxyl peak was found in spectra of both precursor powders calcined below $400{ }^{\circ} \mathrm{C}$, and only in the samples synthesized through slow addition above that temperature. It was thus possible that a precursor composed of a single crystalline material, upon heating results in a denser, oriented aggregate, formed at a lower temperature, however, the extent of organic residuals was greater than for the less structured equivalent precursor.

XRD studies clearly show patterns related to a single polycrystalline material in the slow addition case and at least two in the precursor synthesized by rapid combination of reagents. It is counter-intuitive, then, that the particles synthesized through rapid addition of oxalic acid showed less surface contamination after calcination than those synthesized by slow combination of reagents. This surface contamination can be attributed to the presence of residual carboxylate (see ESI $\dagger$ Fig. 1 and 2). We hypothesize that this is because of the highly viscous nature of the precursor gel formed in this process. As the oxalic acid and zinc acetate solutions are combined, the turbidity and viscosity of their combination increases rapidly; in the case of the precursor formed by slow combination of reagents, it is highly viscous before all the oxalic acid has been added. It is possible that this leads to the formation of a denser intermediate in the case of the slow combination of reagents, and a less closely packed one in the rapidly combined route, and that the intermediate material formed rapidly, on calcination, results in a product with less surface ligation than that formed through slow addition. For the precursor formed by slow combination of reagents, during the early stages of this process, the reactants are in an environment of monotonically increasing oxalic acid concentration and solution viscosity. While oxalic acid molecules added initially react to form zinc oxalate, those added at the latter stages of the experiment, because of the viscous nature of the solution, cannot. Thus the high viscosity of solution limits homogeneous mixing of the gel formed. For the case where oxalic acid is added rapidly, the concentration and viscosity are assumed to be constant while all the oxalic acid molecules are added, however, both solutions contain zinc ions and oxalate molecules in a final ratio of $1: 2$, i.e. four carboxyl groups for each of the divalent zinc centres, and the mixing of the precursor is the only difference between the two methods examined.

In order to investigate the dependence of the properties on the ratio of reagents, precursor gels were synthesized in ratios of zinc acetate to oxalic acid of $1: 1,2: 3$ and $1: 2$. XRD patterns of these gels were recorded after the gels were dried at $100{ }^{\circ} \mathrm{C}$, and calcined at $300{ }^{\circ} \mathrm{C}$ and at $500{ }^{\circ} \mathrm{C}$. The diffraction patterns of the powders synthesized rapidly in a $1: 2$ ratio are shown in Fig. 5. Here, a number of distinct materials were found; zinc oxalate hydrate, $\mathrm{Zn}\left(\mathrm{C}_{2} \mathrm{O}_{4}\right) \cdot 2 \mathrm{H}_{2} \mathrm{O}$, could be related to the most intense peaks shown in the powder heated to $100{ }^{\circ} \mathrm{C}$, anhydrous zinc oxalate, $\mathrm{Zn}\left(\mathrm{C}_{2} \mathrm{O}_{4}\right)$, was present in the powder calcined to $300{ }^{\circ} \mathrm{C}$, and wurtzite zinc oxide was found when the material was calcined to $500{ }^{\circ} \mathrm{C}$. The diffraction pattern of the sample dried at $100{ }^{\circ} \mathrm{C}$ also showed a number of less intense peaks that could not be indexed to any known intermediate oxalate material, these peaks were common to samples made through both slow and rapid synthesis routes in ratios of $1: 2$ and $2: 3$, but not in a $1: 1$ ratio. They were more prominent in gel powders which had a larger excess of oxalic acid, and in those synthesized through rapid addition of oxalic acid. The powders calcined to $300{ }^{\circ} \mathrm{C}$ also showed small peaks at $2 \theta \cong 18.8^{\circ}$, probably remnants of hydrated zinc oxalate; again, these peaks were more prominent in samples synthesized rapidly and in those containing an excess of oxalic acid.

The differences in intensity found in the case above were less pronounced than for those divided as aliquots, this was ascribed to the effect of stirring the solutions. Thus, the reagents were rapidly combined in $1: 1$ and $1: 2$ ratios, and allowed to age for $30 \mathrm{~min}$ at room temperature in lieu of

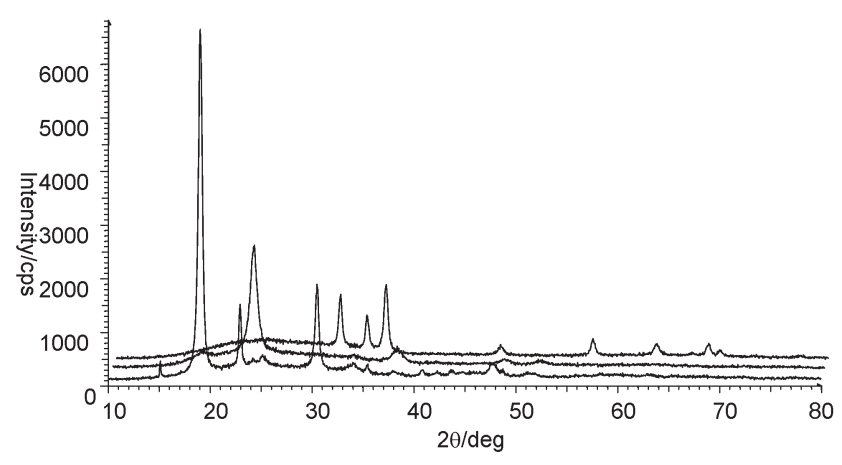

Fig. 5 XRD patterns of powders synthesized through rapid addition of precursor in a $1: 2$ ratio of zinc acetate to oxalic acid, and calcined to $100{ }^{\circ} \mathrm{C}$ (lower), $300{ }^{\circ} \mathrm{C}$ (middle) and $500{ }^{\circ} \mathrm{C}$ (upper pattern). 


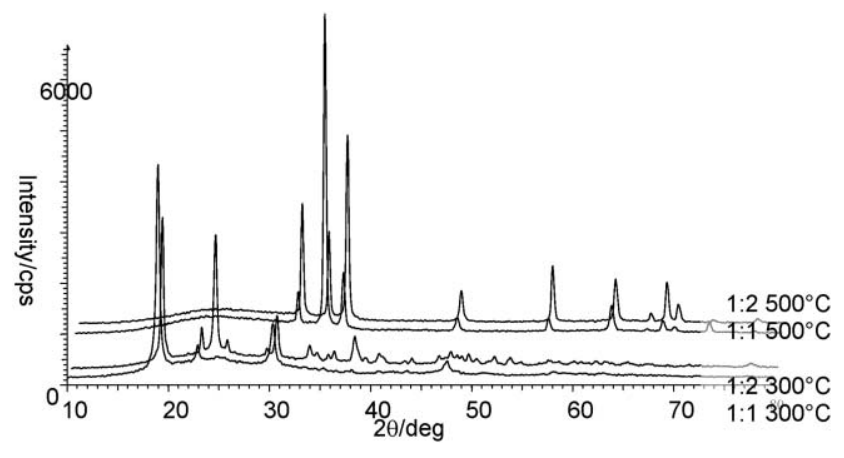

Fig. 6 XRD patterns of powders synthesized in $1: 1$ (lower) and $1: 2$ (upper) ratios of zinc acetate to oxalic acid, and calcined to $300{ }^{\circ} \mathrm{C}$ and $500{ }^{\circ} \mathrm{C}$.

stirring. Diffraction patterns of powders calcined to $300{ }^{\circ} \mathrm{C}$ and $500{ }^{\circ} \mathrm{C}$ are shown in Fig. 6. Hydrated zinc oxalate was found in the $1: 2$ sample calcined to $300{ }^{\circ} \mathrm{C}$ here, but not in that synthesized in a ratio of zinc acetate to oxalic acid of $1: 1$. It can also be seen from the diffraction patterns of the powders calcined at $500{ }^{\circ} \mathrm{C}$ that the $1: 1$ powder contained particles oriented in the $c$-axis direction, while those synthesized in a $1: 2$ ratio had a polycrystalline habit. This correlates with the TEM results shown in Fig 2, which showed for the slowly synthesized powders an oriented aggregation, absent in the purer, rapidly synthesized, powders.

The similarity in the structural and morphological characteristics between the precursors synthesized through slow combination of reagents and those synthesized in a $1: 1$ ratio of reagents is striking, as is that between the rapidly synthesized materials and those synthesized in an excess of acid. In order to eliminate the possibility that the excess of oxalic acid ligands was not a factor in this process, the reaction was undertaken in an acidic environment; solutions were made containing acetic acid in ratios of zinc acetate to acetic acid of $1: 15$ and $1: 87$. It was found that the yield of zinc oxide at $500{ }^{\circ} \mathrm{C}$ decreased dramatically with increasing concentrations of acetic acid, this is the reverse of what was found for increasing concentrations of oxalic acid.

\section{Conclusions}

In the work presented above, we have found that the purity and morphology of zinc oxide nanopowders synthesized by the decomposition of an oxalate precursor is closely associated with the relative concentrations of reagents used. Because of the rapid gelation of this precursor, this dependence extends to the rate at which the reaction proceeds. The interesting result that less surface ligation is found on the sample synthesized through rapid combination of reagents, for which the precursor particles aggregate less closely, has been accounted for by the gelation of the system. As a process, the rapid addition of a material is much more scalable than its slow introduction, so it is a happy coincidence that this method results in a purer compound in this case.

\section{References}

1 H. G. El-Shobaky, M. Mokhtar and G. A. El-Shobaky, Appl. Catal., A: Gen, 1999, 180, 335.

2 G. Glaspell, L. Fuoco and M. Samp El-Shall, J. Phys. Chem. B, $2005, \mathbf{1 0 9}, 17350$

3 B. Bott, T. A. Jones and B. Mann, Sens. Actuators, 1984, 5, 65.

4 M. Huang, S. Mao, H. Feick, H. Yan, Y. Wu, H. Kind, E. Weber, R. Russo and P. Yang, Science, 2001, 292, 1897.

5 Y. Yoshino, T. Makino, Y. Katayama and T. Hata, Vacuum, 2000, 59, 538.

6 H. Nanto, T. Minami and S. J. Takata, J. Appl. Phys., 1986, 60, 482.

7 S. C. Pillai, J. M. Kelly, D. E. McCormack and R. Ramesh, J. Mater. Chem., 2004, 14, 1572.

8 T. Minami, MRS Bull., 2000, 25, 38

9 D. C. Look, Mater. Sci. Eng., B: Solid, 2001, 80, 383.

10 S. C. Pillai, J. M. Kelly, D. E. McCormack, P. O'Brien and R. Ramesh, J. Mater. Chem., 2003, 13, 2586.

11 P. A. Lessing, Ceram. Bull., 1989, 68, 1002.

12 D. Mondelaers, G. Vanhoyland, H. Van den Rul, J. D’Haen, M. K. van Bael, J. Mullens and L. C. Van Puocke, Mater. Res. Bull., 2002, 37, 901.

13 P. M. Pechini, US Pat. \#3330697, 1967.

14 M. Bremer, S. Fischer, H. Langbein, W. Topelmann and H. Scheler, Thermochim. Acta, 1993, 209, 323.

15 K. G. Kanade, B. B. Kale, R. C. Aiyer and B. K. Das, Mater. Res. Bull., 2006, 41, 590.

16 L. Wu, Y. Wu and Y. Lu, Mater. Res. Bull., 2006, 41, 128.

17 ISCD PDF\#25-1029.

18 ISCD PDF\#37-0718. 